\title{
Caso Muelle Flores vs. Perú
}

Sentencia de 06 de marzo de 2019

El 06 de marzo de 2019 la Corte Interamericana de Derechos Humanos dicto Sentencia mediante la cual declaró la responsabilidad internacional del Estado de Perú por la violación a diversos derechos cometidas en perjuicio del señor Oscar Muelle Flores. En particular, encontró que distintas omisiones del Estado constituyeron un incumplimiento en el deber de garantizar el derecho a la tutela judicial efectiva y protección judicial, así como que, las autoridades judiciales no actuaron con el deber de celeridad que exigía la situación de vulnerabilidad en la que se encontraba la víctima, razón por la cual excedieron el plazo razonable. Adicionalmente la Corte determinó que la falta de materialización del derecho a la seguridad social por más de 27 años generó un grave perjuicio en la calidad de vida y la cobertura de salud del señor Muelle, una persona en situación de especial protección por ser persona mayor y en condición de discapacidad. Así mismo, el Tribunal advirtió que la falta de protección judicial afectó el derecho a la pensión que había ingresado al patrimonio de la víctima y por ende se declaró al Estado responsable de la violación del derecho a la propiedad privada. En particular, la Corte encontró que el Estado es responsable por el incumplimiento de las sentencias dictadas a favor del señor Muelle Flores, por la creación de obstáculos derivados de la privatización de la empresa de la cual se jubiló, por no revertir los efectos negativos de dicha privatización y por la ausencia de medidas para remediar dicha situación por un periodo prolongado de tiempo.

En consecuencia, la Corte concluyó que el Estado del Perú es responsable por la violación de los derechos reconocidos en los artículos 8.1, 25.1, 25.2.c), 26, 5 , 11.1, 21.1, y 21.2 de la Convención Americana, en relación con el artículo 1.1, en perjuicio de Oscar Muelle Flores. Asimismo, el Estado es responsable por la violación de su deber de adoptar disposiciones de derecho interno, recogido en el artículo 2 de la Convención Americana, en perjuicio de Oscar Muelle Flores. 


\section{Hechos}

Los hechos del caso se relacionan con la violación del derecho a la tutela judicial efectiva como consecuencia del incumplimiento, durante 24 años, de una sentencia judicial a favor del señor Muelle Flores en el marco de un recurso de amparo en el que se ordenó su reincorporación al régimen pensionario del Decreto Ley $\mathrm{N}^{\circ}$ 20530. La Corte analizo los hechos en relación con i) el primer proceso de amparo; ii) la privatización de la empresa estatal Minera Especial Tintaya S.A.; iii) el segundo proceso de amparo; iv) el proceso contencioso administrativo; v) el proceso de ejecución de la sentencia de amparo del 2 de febrero de 1993, y vi) la normativa sobre pensiones y privatizaciones a partir de 2002.

i. El señor Muelle Flores se jubiló en la empresa estatal de derecho privado Tintaya el 30 de septiembre de 1990 conforme al decreto ley 20530. E1 27 de enero de 1991 ese derecho fue suspendido por la Gerencia de Administración de dicha empresa. Frente a esa suspensión, el señor Muelle Flores interpuso una acción de amparo en el Juzgado Quinto Civil de Lima el cual declaró fundada la demanda y ordenó que se dejara sin efecto la suspensión del régimen de pensiones y compensaciones en perjuicio del señor Muelle Flores. La decisión fue confirmada por la Segunda Sala Civil de la Corte Superior de Lima, y por la Corte Suprema de Justicia, la cual mediante sentencia de 2 de febrero de 1993, confirmó lo resuelto por la Corte Superior y declaró "no haber nulidad" en la sentencia declarando fundada la acción de amparo y ordenando la inaplicabilidad de la suspensión de la Gerencia de Administración de la empresa, restableciendo así sus derechos al estado anterior al de la agresión constitucional.

ii. En lo referente a la privatización de la empresa estatal Minera Especial Tintaya S.A., la Corte constató que fue privatizada en 1994, en el marco del Decreto Legislativo No. 674 "Ley de Promoción de la Inversión Privada de las Empresas del Estado".

iii. El 17 de febrero de 1993 la empresa volvió a disponer la suspensión del pago de algunas pensiones de jubilación a sus ex trabajadores, entre

\footnotetext{
178 DERECHO GLOBAL. ESTUDIOS SOBRE DERECHO Y JUSTICIA
} 
ellas la del señor Muelle Flores, quien interpuso una segunda acción de amparo, mediante la cual solicitó la desaplicación del Acuerdo Directivo No. 023/93, que se le restituyera su derecho a continuar percibiendo su pensión y el pago de una indemnización por el daño causado. El 23 de febrero de 1995 el Décimo Séptimo Juzgado Civil de Lima declaró improcedente la demanda. El fallo fue confirmado por la Primera Sala Civil de la Corte Superior de Justicia de Lima. Posteriormente la Sala de Derecho Constitucional y Social de la Corte Suprema de Justicia declaró improcedente el recurso de amparo interpuesto por el señor Muelle Flores, quien presentó un recurso extraordinario contra esta decisión. El recurso fue resuelto por el Tribunal Constitucional, que revocó la resolución de la Corte Suprema de Justicia, ordenando a la empresa cumplir con el pago continuado de la pensión por cesantía renovable que percibía el señor Muelle Flores, y declaró improcedente el pago de la indemnización solicitada.

iv. La empresa Tintaya S.A. interpuso una demanda en la vía contencioso administrativa a efectos de que se declarara la improcedencia de la reincorporación del señor Muelle Flores al régimen pensionario del Decreto Ley No. 20530. La demanda fue declarada fundada en primera instancia, luego fue apelada y elevada a Sala Contencioso Administrativa de la Corte Superior de Lima, que confirmó la decisión de primera instancia. Esta decisión fue objeto de recurso de nulidad ante la Corte Suprema, que hizo lugar al planteo y declaró infundada la demanda de la empresa Tintaya S.A.

v. En cuanto al procedimiento de ejecución de la sentencia de la Sentencia de la Corte Suprema de Justicia que resolvió el primer amparo interpuesto por el señor Muelle Flores, a la fecha, el proceso de ejecución iniciado en 1993, se encuentra en trámite.

vi. En lo referente a la normativa sobre pensiones y privatizaciones a partir de 2002, la Corte señaló las normas que establecieron el pago de pensiones, así como el organismo pensionista obligado, encontrándose vigente la Ley No. 28449 que precisó las reglas del régimen del Decreto Ley No. 20530, y reitera que es el Ministerio de Economía y Finanzas 
la entidad del Gobierno Nacional responsable por la administración del mismo, norma que fue declarada constitucional por el Tribunal Constitucional en el año 2005.

\section{Excepciones preliminares}

A. Excepción sobre la alegada falta de agotamiento de los recursos interno En ese sentido, el Tribunal constató el Estado no invocó en ningún momento el artículo 46.1 de la Convención ni señaló que no se hubieran agotado los recursos internos, o que la petición fuera inadmisible y únicamente se limitó a describir el estado del proceso. Al respecto, la Corte señaló que "el mero recuento de actuaciones procesales no es suficiente para tener por opuesta una excepción preliminar, siendo que a falta de un alegato claro y oportuno por parte del Estado, se colige que éste no alegó la falta de agotamiento de recursos internos durante la etapa de admisibilidad ante la Comisión" y precisó que dicha fue extemporánea y por ende, la desestimó.

B. Excepción sobre la alegada falta de competencia en razón de la materia y justiciabilidad directa del artículo 26 de la Convención

El Estado señaló que las representantes no pretendían la justiciabilidad de los derechos de la Convención, sino la de los derechos económicos, sociales, culturales y ambientales (en adelante "DESCA"), específicamente del derecho a la seguridad social y sostuvo que la Corte Interamericana era incompetente para pronunciarse sobre la justiciabilidad directa de estos derechos a partir de la interpretación del artículo 26 de la Convención. Para resolver este planteamiento la Corte se remitió a los criterios adoptados en los casos Lagos del Campo Vs. Perú, y Cuscul Pivaral y otros Vs. Guatemala, y reiteró su jurisprudencia en el sentido de que es competente para examinar la pretendida violación del artículo 26 de la Convención y del derecho a la seguridad social que estaría contenido en dicho precepto. De este modo, desestimó la excepción preliminar opuesta por el Estado.

\footnotetext{
180 DERECHO GLOBAL. ESTUDIOS SOBRE DERECHO Y JUSTICIA
} 


\section{Fondo}

La responsabilidad del Estado fue analizada en el siguiente orden: 1) el Derecho a la tutela judicial efectiva en la ejecución de sentencias y privatización de empresas, 2) el plazo razonable en el proceso de ejecución de sentencias, 3) el derecho a la seguridad social en virtud del artículo 26, y 4) el derecho a la propiedad privada.

\section{Derecho a la tutela judicial efectiva en la ejecución de sentencias y privatización de empresas}

La Corte consideró que la ejecución de las sentencias debe ser regida por aquellos estándares específicos que permitan hacer efectivos los principios, inter alia, de tutela judicial, debido proceso, seguridad jurídica, independencia judicial y estado de derecho. La Corte también ha señalado que para lograr plenamente la efectividad de la sentencia la ejecución debe ser completa, perfecta, integral y sin demora.

En el caso concreto, la Corte precisó que no se encuentra en controversia la existencia del derecho a la pensión del señor Muelle Flores o la nivelación de esta conforme a la normativa interna, ni si las decisiones sobre su retiro del régimen del Decreto Ley No. 20530 fueron convencionales o vulneraron el debido proceso. La Corte observó que el Estado no adoptó ninguna medida desde la primera sentencia dictada en 1993 para el cumplimiento rápido y efectivo de lo ordenado por las autoridades judiciales, con el fin de garantizar el derecho a la pensión reconocido judicialmente.

La Corte estimó que el Estado no solo debió cumplir con el pago de la pensión ordenado judicialmente de manera inmediata y con especial diligencia y celeridad al tratarse de un derecho de "carácter alimentario y sustitutivo del salario", sino que debió haber establecido expresa y claramente qué entidad se encargaría del cumplimiento de la decisión, esclareciendo y reconduciendo de oficio, el trámite a la entidad estatal que estaría a cargo del pago correspondiente. Ello no sucedió en el presente caso sino que, por el contrario, dicha responsabilidad fue trasladada a la víctima. 
En consecuencia la Corte determinó que el Estado es responsable por el incumplimiento de las sentencias dictadas a favor del señor Muelle Flores; por la creación de obstáculos derivados de la privatización; por la ineficacia del poder judicial para hacer efectivo el cumplimiento de sus fallos y para revertir los efectos negativos de la privatización. Al mismo tiempo, es responsable por la ausencia de medidas para remediar dicha situación por un periodo prolongado de tiempo. En este sentido, el Estado violó el derecho a la tutela judicial efectiva y protección judicial establecidos en los artículos 25.1 y 25.2 c) en relación con el artículo 1.1, así como del artículo 2 de la Convención Americana, en perjuicio del señor Oscar Muelle Flores.

\section{El plazo razonable}

En cuanto al plazo razonable en relación con la etapa de ejecución de sentencias, la Corte resalta que dicho plazo debe ser más breve debido a la existencia de una decisión firme en relación con una materia concreta. Para la Corte, es dable destacar que desde las sentencias dictadas en 1993 y 1999 hasta la fecha, han transcurrido más de 26 y 19 años, respectivamente, los que en una persona de avanzada edad y carente de recursos económicos, han ocasionado un impacto en su situación jurídica. Teniendo en cuenta lo anterior, la Corte concluyó que las autoridades judiciales no actuaron con el deber de celeridad que exigía la situación de vulnerabilidad en la que se encontraba el señor Muelle Flores, razón por la cual excedieron el plazo razonable del proceso, lo cual vulnera el derecho a las garantías judiciales establecido en el artículo 8.1 de la Convención Americana, en relación con el artículo

1.1 del mismo instrumento, en perjuicio de Oscar Muelle Flores. 


\section{Derecho a la seguridad social}

Por otra parte la Corte se pronunció por primera ocasión respecto del derecho a la seguridad social, en particular sobre el derecho a la pensión, de manera autónoma, como parte integrante de los DESCA. Sobre este particular señalo que del artículo 45 de la Carta de la OEA, interpretado a la luz de la Declaración Americana y de otros tratados e instrumentos internacionales de derechos humanos se puede derivar elementos constitutivos del derecho a la seguridad social, como por ejemplo, que es un derecho que busca proteger al individuo de contingencias futuras, que de producirse ocasionarían consecuencias perjudiciales para la persona, por lo que deben adoptarse medidas para protegerla.

En particular el derecho a la seguridad social buscar proteger al individuo de situaciones que se presentarán cuando éste llegue a una edad determinada en la cual se vea imposibilitado física o mentalmente para obtener los medios de subsistencia necesarios para vivir un nivel de vida adecuado, lo que a su vez podría privarlo de su capacidad de ejercer plenamente el resto de sus derechos. Esto último también da cuenta de uno de los elementos constitutivos del derecho, ya que la seguridad social deberá ser ejercida de modo tal que garantice condiciones que aseguren la vida, la salud y un nivel económico decoroso.

En el caso concreto, el señor Muelle Flores dejó de recibir su pensión el año 1991. Debido a la falta de cumplimiento y ejecución de las sentencias a nivel interno, el derecho a la pensión del señor Muelle Flores no fue garantizado de manera oportuna, sino que por el contrario, hasta la actualidad dichas sentencias no han sido ejecutadas ya que el proceso correspondiente sigue abierto, por lo que los mecanismos existentes no lograron la concretización material del derecho, lo que constituyó una violación del derecho a la seguridad social.

Por otra parte, la Corte determinó que en un contexto de no pago de la pensión reconocida judicialmente, los derechos a la seguridad social, a la integridad personal y la dignidad humana se interrelacionan, y en ocasiones, la vulneración de uno genera directamente la afectación del otro, situación que se acentúa en el caso de las personas mayores. La Corte determinó que la falta de materialización del derecho a la seguridad social por más de 27 años por el no pago de la pensión 
de jubilación generó un grave perjuicio en la calidad de vida y la cobertura de salud del señor Muelle, una persona en situación de especial protección por ser una persona mayor con discapacidad. La vulneración generada por la falta de pago de la pensión se extendió más allá del plazo razonable debido, y al ser este el único ingreso de la víctima, la ausencia prolongada del pago generó indefectiblemente una precariedad económica que afectó la cobertura de sus necesidades básicas, y por ende también su integridad psicológica y moral, así como su dignidad.

\section{Derecho a la propiedad privada}

La Corte estimó que el derecho a la pensión nivelada que adquirió la víctima y que se encontraba en vigencia en el Perú hasta el año 2004, así como el derecho a su pensión conforme a las reformas constitucionales acontecidas en dicha fecha, generó un efecto en el patrimonio del señor Muelle Flores. En efecto, el derecho a recibir una pensión fue adquirido luego de que el señor Muelle dejara de prestar servicios a la institución para la cual laboró, al haber cumplido con los requisitos para ello y con el pago de las contribuciones correspondientes, de conformidad con la normativa interna peruana. En este sentido, tal patrimonio se vio afectado directamente por la decisión del Estado de suspender los pagos, así como por el incumplimiento y la falta de ejecución de las sentencias judiciales. En consecuencia de lo anterior y teniendo en cuenta que la falta de protección judicial afectó el derecho a la pensión que había ingresado al patrimonio de la víctima, la Corte declaró que el Estado violó el derecho a la propiedad privada reconocido en el artículo 21.1 y 21.2, en relación con los artículos 25.1, 25.2.c), 26 y 1.1 de la Convención Americana, en perjuicio del señor Muelle Flores. 